Arq. Bras. Med. Vet. Zootec., v.57, n.2, p.191-195, 2005

\title{
Estudo da ação inflamatória aguda do tiopental intraperitoneal em ratos
}

[Acute inflammatory action of tiopental intraperitoneal in rats]

\author{
A.B. Carregaro ${ }^{1}$, M.B. Castro $^{1}$, F.S. Martins ${ }^{2}$ \\ ${ }^{1}$ Universidade de Franca \\ Av. Doutor Armando Salles Oliveira, 201 \\ 14440-000 - Franca, SP \\ ${ }^{2}$ Estudante de graduação - Universidade de Franca
}

\begin{abstract}
RESUMO
Determinou-se a ação inflamatória aguda do tiopental intraperitoneal (IP) utilizando-se 72 ratos, divididos em grupo-tratado $(40 \mathrm{mg} / \mathrm{kg}$ de tiopental a $2,5 \%$ IP) e grupo-controle $(0,25 \mathrm{ml}$ de solução fisiológica IP). Para determinar o processo inflamatório, colheu-se o lavado peritoneal às 2, 6, 12, 24 e 48h após a inoculação. Os animais foram anestesiados com isoflurano e submetidos à eutanásia por secção dos vasos cervicais. Administraram-se $5 \mathrm{ml}$ de solução fisiológica heparinizada por via IP e, após homogeneização, divulsionou-se o peritôneo e colheu-se a amostra. Determinaram-se a dosagem de proteínas plasmáticas (PP), a contagem global (CGL) e a diferencial (CDL) de leucócitos. Não foi observada diferença na PP entre os grupos em nenhum momento exceto às $2 \mathrm{~h}$. Entre os momentos, a dosagem foi superior às $6 \mathrm{e} 12 \mathrm{~h}$ nos dois grupos. Não houve diferença entre os grupos para a CGL. Entre os momentos, a CGL diferiu dos demais às $6 \mathrm{~h}$ em ambos os grupos. Verificou-se o mesmo perfil para a CDL entre os grupos exceto para os eosinófilos às $6 \mathrm{~h}$. Entre os momentos, os valores foram diferentes em relação aos neutrófilos em ambos os grupos, às 6 e 12h. Observou-se reação inflamatória aguda no processo provavelmente desencadeada pela ação mecânica da injeção. A eosinofilia observada no grupo-tratado após 6h sugere uma certa ação irritante do tiopental.
\end{abstract}

Palavras-chave: inflamação, rato, tiopental

\begin{abstract}
The acute inflammatory action of thiopental intraperitoneal (IP) in rats was studied. Seventy two animals were divided in treated $(40 \mathrm{mg} / \mathrm{kg}$ of thiopental, $2.5 \% \mathrm{IP})$ and control $(0.25 \mathrm{ml}$ of saline solution IP) rats. In order to evaluate the inflammatory process, peritoneal fluid was taken at $2 \mathrm{~h}, 6 \mathrm{~h}, 12 \mathrm{~h}, 24 \mathrm{~h}$ e $48 \mathrm{~h}$ after drug administration. The animals were anesthetized with isoflurane and submitted to euthanasia through cervical vessels section. Five millilitres of heparinized saline solution were injected IP, homogenized by abdomen massage and then withdrawn. Plasma protein (PP), global leukocyte count (GLC) and differential leukocyte count (DLC) were analysed. No difference in PP intergroup at any moment was observed, but at $2 \mathrm{~h}$. Intragroup, PP was higher between 6 and $12 \mathrm{~h}$ in both groups. There was no statistical difference of GLC intergroup. There was a difference $(P<0.05)$ of $G L C$ results between groups at 6 h post-injection. There was a similar pattern of DLC intergroups, except eosinophil cells at $6 \mathrm{~h}$. Intragroup cell counts of neutrophils were different $(P<0.05)$ in both groups at 6 and $12 \mathrm{~h}$. The acute inflammatory reaction observed was probably trigged by the mechanically action of injection. The eosinophilia observed in treated group after 6h suggests some irritant action of thiopental.
\end{abstract}

Keywords: rat, inflammation, thiopental

Recebido para publicação em 11 de dezembro de 2003

Recebido para publicação, após modificações, em 25 de maio de 2004

E-mail: carregaro@anestciruvet.com.br 


\section{Carregaro et al.}

\section{INTRODUÇÃO}

Atualmente, devido à facilidade de produção, manutenção e manuseio, considerável parcela das pesquisas científicas é realizada com roedores em que, por vezes, se faz necessária a imobilização temporária do animal. A anestesia inalatória nesses animais apresenta limitações, principalmente devido a intubação orotraqueal (Massone, 2003). Com isso, têm-se utilizado barbitúricos de ultracurta duração, como o tiopental sódico, os quais proporcionam um período hábil anestésico adequado para a maioria dos procedimentos clínicos ou cirúrgicos (Flecknell, 1996; Massone, 2003).

Em ratos, o tiopental sódico é utilizado pela via intraperitoneal em doses de 30 a $50 \mathrm{mg} / \mathrm{kg}$ (Thurmon et al., 1996). A anestesia se faz presente em um a dois minutos com duração de 10 a 15 minutos (Flecknell, 1996; Massone, 2003). Produz decréscimo tanto na pressão arterial quanto no débito cardíaco, apesar da discreta taquicardia (Kerger et al., 1997). Há inibição dos baroceptores aórtico e carotídeo, agravando a depressão cardiovascular (Fan et al., 1996). Observa-se, ainda, redução na freqüência respiratória, aumento na $\mathrm{PaCO}_{2}$ e conseqüente acidose respiratória (Svenden e Carter, 1985).

A diminuta massa corporal dos ratos faz com que a administração intravenosa de qualquer substância seja dificultada. Assim, geralmente as vias intraperitoneal (IP) e subcutânea são as mais empregadas. Com isso, não há a possibilidade de administração gradual de anestésicos, sendo realizada em uma única dose. Ao adotar um volume padrão de anestésico para todos os animais, corre-se o risco de subdoses, impossibilitando o procedimento cirúrgico, ou superdoses que, além de prolongar o período hábil anestésico, proporcionaria significativo aumento nos efeitos deletérios, podendo culminar em morte.

Uma das adversidades na utilização do tiopental é a administração acidental perivascular. Devido à diferença de $\mathrm{pH}$ entre a solução que contém o fármaco e o meio, há uma irritação local com sinais clínicos de dor e inflamação, podendo levar à necrose em casos extremos (Davies, 1979; Hall e Clarke, 1987; Mao et al., 1997; Trim, 1999).
A cavidade peritoneal, apesar de proporcionar absorção mais rápida que a via subcutânea, não propicia condição igual à intravenosa. Com isso, pode-se pensar em uma possível irritação nos constituintes desta, como peritôneo e vísceras, já que o fármaco ficará por algum tempo na cavidade.

Este trabalho teve o objetivo de determinar a ação inflamatória aguda do tiopental, administrado por via IP, em ratos.

\section{MATERIAL E MÉTODO}

Foram utilizados 72 ratos da raça Wistar, machos adultos, com peso entre 180 e $250 \mathrm{~g}$, provenientes do Biotério da Universidade de Franca.

Para avaliar a ocorrência de processo inflamatório, os animais foram divididos em dois grupos, controle e tratado, e subgrupos de acordo com o tempo de colheita do lavado peritoneal. O grupo-controle recebeu $0,25 \mathrm{ml}$ de solução fisiológica e o tratado $40 \mathrm{mg} / \mathrm{kg}$ de tiopental sódico a 2,5\%, ambos por via IP. Para a contagem de células, realizou-se a colheita às 2 , $6,12,24$ e 48h pós-administração de tiopental ou solução salina.

Para a colheita do lavado, os animais foram submetidos à anestesia inalatória com isoflurano ${ }^{1}$ e posterior exsangüinação através de secção dos vasos cervicais. Após isso, divulsionou-se a pele da região abdominal ventral e administraram-se $5 \mathrm{ml}$ de solução fisiológica contendo EDTA $(10 \%, \mathrm{pH} 7,4)$, com auxílio de uma agulha $13 \times 4$ a fim de promover o mínimo trauma na vasculatura peritoneal. Massageou-se o abdome do animal para homogeneizar o lavado. Incisouse o peritôneo e colheu-se o lavado peritoneal com uma pipeta Pasteur.

Colhido o lavado, retirou-se uma alíquota para contagem global de leucócitos ${ }^{2}$. O restante foi centrifugado por três minutos a $626 \mathrm{~g}$. Separaram-se o sobrenadante, para dosagem de proteínas plasmáticas ${ }^{3}$, e o sedimento, para contagem diferencial de leucócitos pela coloração HE, por microscopia óptica.

\footnotetext{
${ }^{1}$ Isoflurane ${ }^{\circledR}$. Cristália Prod. Farm. Ltda, SP.

${ }^{2}$ Celm CC 530. Cia Equip. Lab. Mod., SP.

${ }^{3}$ Labquest ${ }^{\circledR}$. Labtest Diagnóstica, MG.
} 
Utilizou-se análise de variância (Hoel, 1974) para repetições múltiplas (amostras nãopareadas), para avaliação de proteínas plasmáticas e para contagem global de leucócitos e contagem diferencial de leucócitos, seguida pelo teste Tukey, quando necessário, para comparação de médias. A comparação entre os grupos foi realizada pelo teste $t$. Os valores foram expressos em média \pm desvio padrão e considerados significativos quando $\mathrm{P}<0,05$.

\section{RESULTADOS}

Observou-se o mesmo perfil na dosagem de proteínas plasmáticas entre os grupos em todos os momentos exceto às $2 \mathrm{~h}$, em que o grupotratado apresentou dosagem superior à do controle $(\mathrm{P}<0,05)$. Entre os momentos, houve elevação das proteínas plasmáticas no lavado peritoneal em ambos os grupos às $6 \mathrm{e} 12 \mathrm{~h}$, acima de $140 \mathrm{mg} / \mathrm{dl} \quad(\mathrm{P}<0,05)$. Após isso, os valores oscilaram entre 110 e $130 \mathrm{mg} / \mathrm{dl}$ (Fig. 1).

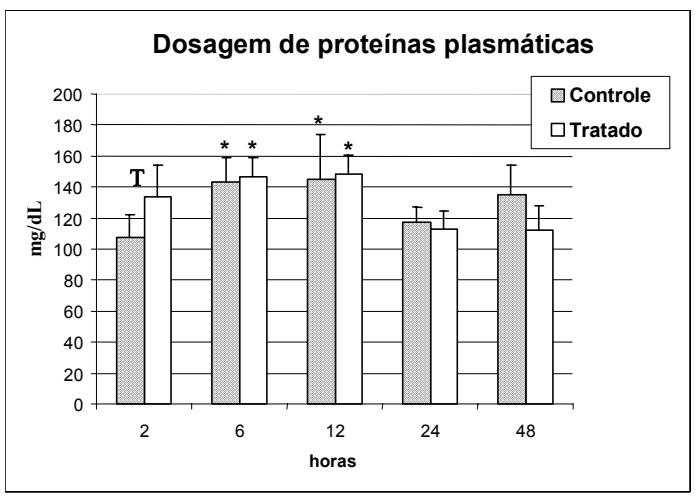

Figura 1. Dosagem de proteínas plasmáticas no lavado peritoneal de ratos submetidos à anestesia por tiopental.

* Diferença significativa entre os momentos dentro do grupo $(\mathrm{P}<0,05)$.

$\mathrm{T}$ : diferença significativa entre os grupos no mesmo momento $(\mathrm{P}<0,05)$.

A contagem global de leucócitos foi semelhante nos dois grupos, seguindo o mesmo padrão no decorrer dos momentos, não diferindo entre eles. Entre os tempos, observou-se aumento às 6h, obtendo-se pico leucocitário próximo a $10 \times 10^{3} / \mathrm{ml} \quad(\mathrm{P}<0,05)$. Após isso, as contagens oscilaram entre $6-8 \times 10^{3} / \mathrm{ml}$ leucócitos (Fig. 2).

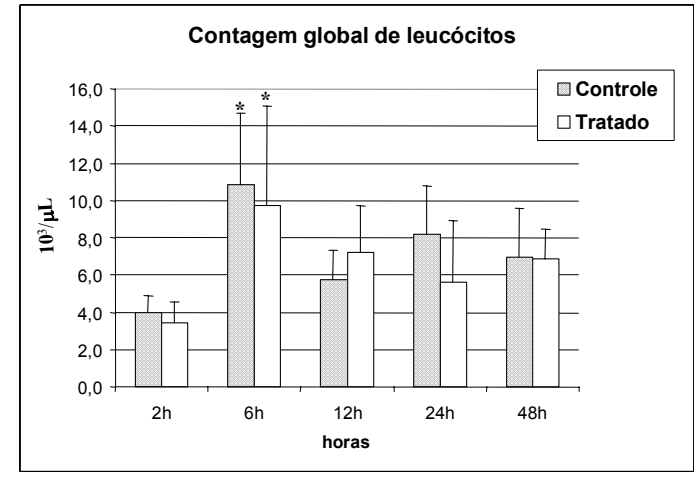

Figura 2. Contagem global de leucócitos em lavado peritoneal de ratos submetidos à anestesia por tiopental.

* Diferença significativa entre os momentos dentro do grupo $(\mathrm{P}<0,05)$.

Mediante contagem diferencial de leucócitos, observou-se diferença na migração celular, de acordo com os tempos (Fig. 3). Nos momentos 6 e $12 \mathrm{~h}$, houve elevação na contagem de neutrófilos em ambos os grupos, mas não houve diferença entre grupos. O grupo-controle diferiu estatisticamente em relação às $2 \mathrm{~h}(\mathrm{P}<0,05)$. Em ambos os grupos predominaram neutrófilos íntegros e segmentados.

A contagem de eosinófilos seguiu um perfil constante em todos os momentos, com aumento na migração deles no grupo-tratado em relação ao controle às 2 e 6 h, diferindo estatisticamente entre si nesse último momento.

Os dois grupos apresentaram o mesmo perfil na contagem de mononucleares, e, como esperado, foi inversamente proporcional à contagem de neutrófilos. A porcentagem de neutrófilos foi menor desde 6 até $24 \mathrm{~h}$ pós-administração. 

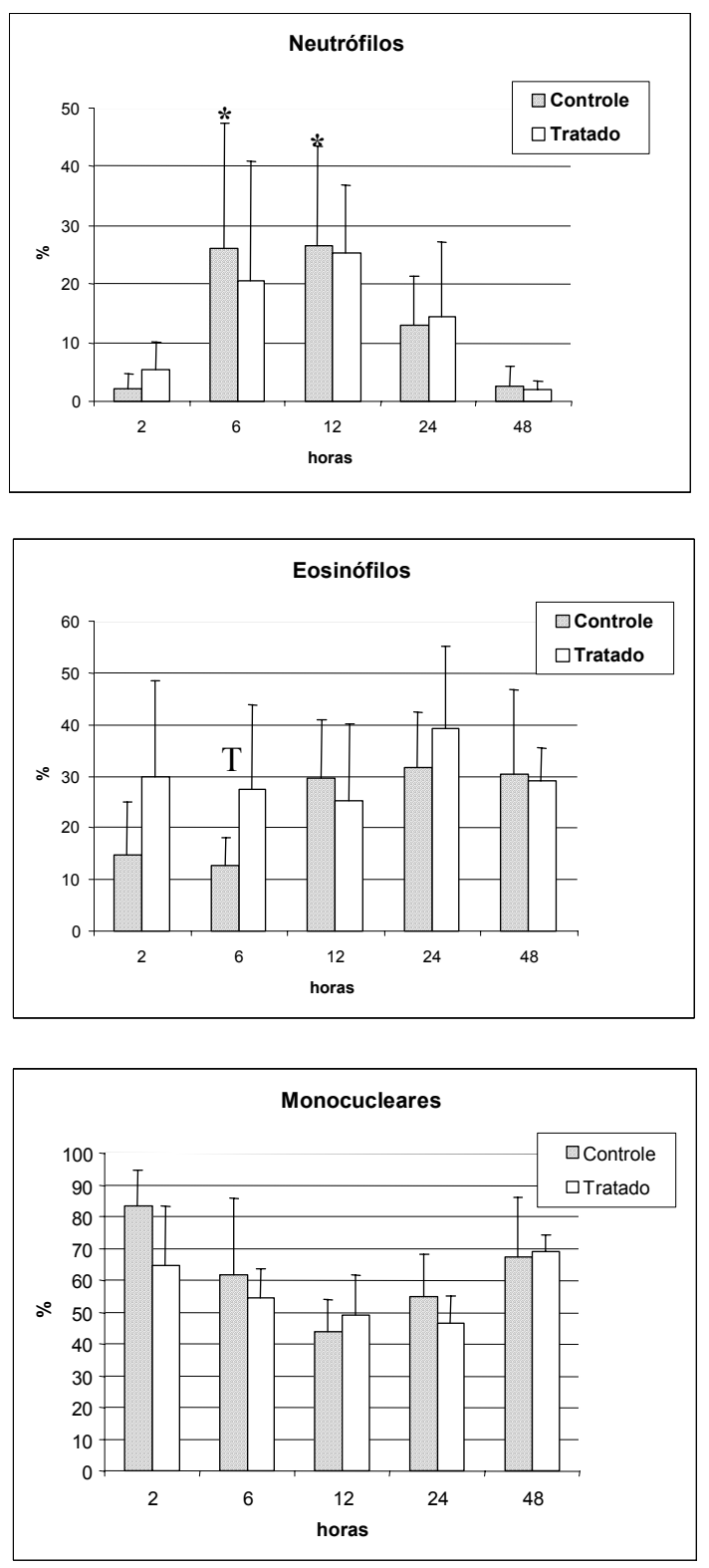

Figura 3. Contagem diferencial de leucócitos em lavado peritoneal de ratos submetidos à anestesia por tiopental.

* Diferença significativa entre os momentos dentro do grupo $(\mathrm{P}<0,05)$. $\mathrm{T}$ : diferença significativa entre os grupos no mesmo momento $(\mathrm{P}<0,05)$.

\section{DISCUSSÃO}

O pKa do tiopental é de 7,6 e o pH da formulação utilizada na rotina anestésica é diferente do $\mathrm{pH}$ do peritôneo (Cristensen et al., 1983). Essa situação pode promover reação inflamatória de origem química, o que desencadearia uma reação contra o agente irritante, podendo ocorrer desde uma simples dor local e rubor até necrose (Davies, 1979; Hall e Clarke, 1987; Mao et al., 1997; Trim, 1999).

A partir das dosagens de proteínas plasmáticas, verificou-se um perfil homogêneo entre os grupos. A diferença entre os grupos nas primeiras duas horas não se manteve ao longo dos momentos, podendo-se afirmar que a reação de hipersensibilidade promovida pelo tiopental não caracterizou desequilíbrio na permeabilidade vascular, fato observado em reações inflamatórias agudas. Soma-se a isso as diferenças, quando comparadas dentro de cada grupo. Mesma com aumento significativo às $6 \mathrm{e}$ 12 horas, não se observou discrepância entre os momentos, comprovando a integridade vascular.

A contagem global de leucócitos evidenciou aumento na migração celular $6 \mathrm{~h}$ pós-injeção. Entretanto, não se pôde justificar o fato pelo fármaco utilizado, uma vez que em ambos os grupos observou-se o acontecido. Desse modo, a quimiotaxia pode ter sido desencadeada pelo modo de administração, ou seja, o trauma da agulha no peritôneo deve ter sido o principal responsável pelo aumento quimiotático.

Cotran et al. (1989) citaram que os processos inflamatórios ocasionados por material estéril estranho ao organismo, como os utilizados em cirurgia, não chegam a promover sintomas clínicos e há apenas a possibilidade de granulomas, fibroses ou aderências. A reação inflamatória observada mediante contagem global sugere que o processo traumático não promoveu maiores danos aos tecidos envolvidos, pois após $6 \mathrm{~h}$ o número total de leucócitos diminuiu.

A contagem diferencial de células demonstrou um fato característico de processo inflamatório agudo, em que o número de neutrófilos foi superior nos momentos 6 e 12 horas em relação aos outros. Segundo Cotran et al. (1989), os neutrófilos predominam nas primeiras 24 horas do processo inflamatório devido, principalmente, à ativação do processo quimiotático ser mais rápida do que para outras células.

O predomínio de neutrófilos íntegros e segmentados reforça a sugestão de reação de 
hipersensibilidade. Eles apresentam-se idênticos aos do sangue circulante, podendo inclusive ser hipersegmentados, sugerindo fluido asséptico. Ao contrário, quando degenerados, indicam a presença de endotoxinas e exotoxinas, as quais causam aumento da permeabilidade da membrana e subseqüente degeneração hidrópica (Olson et al., 1995) A presença desse tipo de neutrófilo sugere infecção bacteriana, o que não foi observado neste estudo.

Jones et al. (2000) salientaram que em reações de hipersensibilidade há predominância de eosinófilos, o que pode explicar, na maioria dos momentos estudados, a maior porcentagem deles em relação à de neutrófilos. A maior incidência de células eosinofílicas no grupo-tratado às $6 \mathrm{~h}$ sugere uma resposta mais exacerbada atribuída à ação do tiopental, caracterizando uma resposta quimiotática para o fármaco. Tais observações divergem do estudo realizado por Krumholz et al. (1999), que demonstraram o poder inibitório na quimiotaxia eosinofílica com tiopental.

A resposta ao procedimento anestésico com tiopental foi moderada quando comparada à do controle. Os dois grupos apresentaram processo inflamatório agudo, o que pode ser explicado pelo trauma da injeção. Entretanto, não se deve descartar a ação irritante do tiopental, já que no grupo tratado houve migração eosinofílica maior que no controle.

Assim, deve-se atentar para a contagem de células inflamatórias em estudos que utilizem substâncias irritantes nos modelos inflamatórios, principalmente na fase aguda, para não incorporarem o aumento leucocitário, decorrente do traumatismo da injeção do tiopental, ao atribuído a esse medicamento.

\section{REFERÊNCIAS BIBLIOGRÁFICAS}

CHRISTENSEN, J.H.; ANDERSEN, F.; JENSEN, E.B. The binding of thiopental to human serum albumin at variable $\mathrm{pH}$ and temperature. Acta Pharmacol. Toxicol., v.5, p.364-70, 1983.

COTRAN, R.S.; KUMAR, V.; ROBBINS, S.L. Robbins pathologic basis of disease. 4.ed. Philadelphia: W.B. Saunders, 1989. 1519p.

DAVIES, D.D. Local complications of thiopentone injection. A further report. Br. J. Anaesth., v.12, p.147-149, 1979.

FAN, W.; REYNOLDS, P.J.; ANDRESEN, M.C. Baroreflex frequency-response characteristics to aortic depressor and carotid sinus nerve stimulation in rats. Am. J. Physiol., v.271, p.2218-2227, 1996.

FLECKNELL, P.A. Laboratory animal anaesthesia. 2.ed. London: Academic, 1996. 274p.

HALL, L.W.; CLARKE, K.W. Anestesia veterinária. 8.ed. São Paulo: Manole, 1987. 680p.

HOEL, P.G. Elementary statistics. 3.ed. New York: John Wiley \& Sons, 1974. 368p.

JONES, T.C.; HUNT, R.D.; KING, N.W. Patologia veterinária. 6.ed. São Paulo: Manole, 2000. 1415p.

KERGER, H.; SALTZMAN, D.J.; GONZALES, A. et al. Microvascular oxygen delivery and intestinal oxygenation during sodium pentobarbital anesthesia. Anesthesiology, v.86, p.372-386, 1997.

KRUMHOLZ, W.; ABDULLE, O.; KNECHT, J. et al. Effects of i.v. anaesthetic agents on the chemotaxis of eosinophils in vitro. Br. J. Anesth., v.2, p.333-335, 1999.

MAO, C.C.; HSIEH, Y.C.; HSEU, S.S. et al. EMLA cream and lidocaine local injection in the treatment of extravenous thiopental injection - a case report. Acta Anaesthesiol. Sin., v.2, p.103-6, 1997.

MASSONE, F. Anestesiologia veterinária. 4.ed. Rio de Janeiro: Guanabara Koogan, 2003. 326p.

MEADOWS, R.L.; MacWILLIAMS, P.S. Chylous effusions reviseted. Vet. Clin. Pathol., v.23, p.54-62, 1994.

OLSON, N.C.; HELLYER, P.W.; DODAM, J.R. Mediators and vascular effects in response to endotoxin - Review. Br. Vet. J., v.151, p.489-522, 1995.

SVENDEN, P.; CARTER, A.M. Influence of injectable anaesthetic combinations on blood gas tensions and acid-base status in laboratory rats. Acta Pharmacol. Toxicol., v.57, p.1-7, 1985.

THURMON, J.C.; TRANQÜILLI, W.J.; BENSON, G.J. Lumb \& Jone's veterinary anesthesia. 3.ed. Baltimore: Williams \& Wilkins, 1996. 928p.

TRIM, C.M. Anesthetic emergencies and complications. In: PADDLEFORD, R.R. Manual of small animal anesthesia. 2.ed. Philadelphia: W.B. Saunders, 1999. 423p.

TYLER, D.R.; COWELL, R.L. Evaluation of pleural and peritoneal effusions. Vet. Clin. North Am.: Small Anim. Pract., v.19, p.743-769, 1989.

WILKINSON, P.C. Chemotaxis and inflammation. 2.ed. Edinburgh: Churchill-Livingstone, 1982. p.1249. 